\title{
Aphid and Plant Volatiles Induce Oviposition in an Aphidophagous Hoverfly
}

\author{
Francois J. Verheggen - Ludovic Arnaud • \\ Stefan Bartram • Marie Gohy • Eric Haubruge
}

Received: 17 September 2007 / Revised: 16 November 2007 / Accepted: 16 January 2008 / Published online: 6 February 2008

(C) Springer Science + Business Media, LLC 2008

\begin{abstract}
Episyrphus balteatus DeGeer (Diptera, Syrphidae) is an abundant and efficient aphid-specific predator. We tested the electroantennographic (EAG) response of this syrphid fly to the common aphid alarm pheromone, (E)- $\beta$ farnesene $(\mathrm{E} \beta \mathrm{F})$, and to several plant volatiles, including terpenoids (mono- and sesquiterpenes) and green leaf volatiles ( $\mathrm{C} 6$ and $\mathrm{C} 9$ alcohols and aldehydes). Monoterpenes evoked significant EAG responses, whereas sesquiterpenes were inactive, except for the aphid alarm pheromone $(\mathrm{E} \beta F)$. The most pronounced antennal responses were elicited by six and nine carbon green leaf alcohols and aldehydes [i.e., (Z)3-hexenol, (E)-2-hexenol, (E)-2-hexenal, and hexanal]. To investigate the behavioral activity of some of these EAGactive compounds, E. balteatus females were exposed to $R$-(+)-limonene (monoterpene), (Z)-3-hexenol (green leaf alcohol), and E $\beta F$ (sesquiterpene, common aphid alarm pheromone). A single E. balteatus gravid female was exposed for $10 \mathrm{~min}$ to an aphid-free Vicia faba plant that was co-located with a semiochemical dispenser. Without additional semiochemical, hoverfly females were not attracted to this plant, and no oviposition was observed.
\end{abstract}

F. J. Verheggen $(\bowtie) \cdot$ L. Arnaud $\cdot$ E. Haubruge

Department of Functional and Evolutionary Entomology,

Gembloux Agricultural University,

Gembloux, Belgium

e-mail: entomologie@fsagx.ac.be

S. Bartram

Department of Bioorganic chemistry,

Max Planck Institute for Chemical Ecology,

Jena, Germany

M. Gohy

Unité Technique COVs Qualité de l'air,

Institut scientifique de service public,

Liege, Belgium
The monoterpene $R-(+)$-limonene did not affect the females' foraging behavior, whereas (Z)-3-hexenol and $\mathrm{E} \beta \mathrm{F}$ increased the time of flight and acceptance of the host plant. Moreover, these two chemicals induced oviposition on aphid-free plants, suggesting that selection of the oviposition site by predatory hoverflies relies on the perception of a volatile blend composed of prey pheromone and typical plant green leaf volatiles.

Keywords Episyrphus balteatus · Predator · Plant-insect interaction - Oviposition induction · Green leaf volatiles .

Terpenoids $\cdot(E)-\beta$-Farnesene $\cdot$ Electroantennography $\cdot$ EAG

\section{Introduction}

Episyrphus balteatus DeGeer (Diptera: Syrphidae) is the most frequently encountered syrphid species at aphidinfested sites in temperate regions (Schneider 1969), and one of the most efficient aphid-specific predators (Entwistle and Dixon 1989; Tenhumberg and Poehling 1991). Because syrphid larvae have limited dispersal abilities (Chandler 1969), oviposition site selection has an important impact on offspring performance. Several studies have addressed a wide range of parameters that influence the foraging and oviposition behavior of aphid natural enemies. Those studied so far are (1) aphid species and their associated chemicals (Budenberg and Powell 1992; Bargen et al. 1998; Sadeghi and Gilbert 2000a, b; Zhu et al. 2005; Almohamad et al. 2007; Verheggen et al. 2007a), (2) physical and chemical characteristics of plants associated with aphid species (Chandler 1968; Sanders 1983; Vanhaelen et al. 2001, 2002; Tumlinson et al. 1992; Zhu et al. 2005; Videla et al. 2006; Almohamad et al. 2007; Harmel et al. 2007), (3) aphid colony size and density (Bargen et al. 1998; Scholz and 
Poehling 2000; Sutherland et al. 2001), (4) age of the hoverfly female (Sadeghi and Gilbert 2000c; Frechette et al. 2004) and (5) floral characters (Sutherland et al. 1999).

Location of herbivorous prey by carnivorous arthropods is known to be mediated by many semiochemicals emitted by the prey or its host plants (Dicke and Sabelis 1988; Vet and Dicke 1992; Harmel et al. 2007). Many studies on tritrophic interactions between plants, herbivorous insects, and natural enemies have demonstrated that attack-induced plant volatiles (synomones) may attract carnivorous species (Nordlund and Lewis 1976; Turlings et al. 1990; Vet and Dicke 1992; Tumlinson et al. 1992; Turlings and Tumlinson 1992; De Moraes et al. 2001). Plants infested by herbivores can qualitatively and/or quantitatively change their volatile emissions. These emissions usually consist of terpenoids (monoterpenes and sesquiterpenes) and green leaf volatiles (GLVs; alcohols, aldehydes, or esters), the latter being specifically released just upon tissue damage (Paré and Tumlinson 1997; Farag and Paré 2002; Tholl et al. 2006).

Compared to the large body of information on parasitoids, less information is available on those chemical cues that guide predators during location and acceptance of oviposition sites (Steidle and van Loon 2002). Hoverflies are subjected to various chemical blends when searching for an oviposition site. These blends consist of plant and insect semiochemicals such as $(E)-\beta$-farnesene $(\mathrm{E} \beta \mathrm{F})$, the main component of the alarm pheromone of most aphid species (Nault et al. 1973; Francis et al. 2005a). This sesquiterpene has been found to act as a kairomone for several aphid predators, including E. balteatus larvae, Harmonia axyridis adults, and Adalia bipunctata larvae and adults (Francis et al. 2004, 2005b; Verheggen et al. 2007a). More than 20 additional chemicals, including $\alpha$ and $\beta$-pinene, cymene, $\alpha$-phellandrene, or limonene, were found by Francis et al. (2005a) to be released by some aphid species. These volatiles are also commonly found in the headspace of many plant families, such as the Solanaceae, Fabaceae, or Brassicaceae (Agelopoulos et al. 1999; Farag and Paré 2002; Verheggen et al. 2005; Harmel et al. 2007). Terpenoids and GLVs are potential semiochemicals that are used by aphid predators, such as syrphids, lady beetles, or lacewings, to locate their prey (Zhu et al. 1999; Steidle and van Loon 2002; Harmel et al. 2007).

In this study, we investigated the olfactory perception and behavioral activity of various plant volatiles and the common aphid alarm pheromone $(\mathrm{E} \beta \mathrm{F})$ to highlight those that may act on the prey-seeking behavior of E. balteatus.

\section{Methods and Materials}

Chemicals All chemicals, except E $\beta F$, were purchased from Sigma-Aldrich (Chemie Gmbh, Steinheim, Germany) and had chemical purity $>97 \%$ [determined by gas chromatography (GC)]. E $\beta F$ was synthesized from farnesol (Tanaka et al. 1975) and had a chemical purity of $98 \%$ (also determined by GC).

Biological Material All plants, aphids, and hoverflies were reared in climate-controlled rooms (16 hrs light photoperiod; $70 \%$ RH; $20 \pm 2^{\circ} \mathrm{C}$ ). Broad beans (Vicia faba L.) were grown in plastic pots $(9 \times 8 \mathrm{~cm})$ filled with a mixture of vermiculite and perlite $(1 / 1)$ and were used as host plants for the pea aphid, Acyrthosiphon pisum Harris. Adult E. balteatus were reared in cages $(75 \times 60 \times 90 \mathrm{~cm})$ and fed with pollen, sugar, and water ad libitum. Hoverfly oviposition was induced by placing broad beans in the cage for 3 hrs. E. balteatus larvae were fed with A. pisum and pupae were placed in aerated plastic boxes $(14 \times 11 \times$ $4 \mathrm{~cm}$ ) until hatching. Experiments were carried out with 2- to 4-wk-old adults.

Electroantennography The hoverfly was immobilized by covering its abdomen and thorax with modeling clay. This setup enabled the recording of electroantennograms for a longer time period than if the antenna was excised (Verheggen et al. 2007b). Two glass $\mathrm{Ag}-\mathrm{AgCl}$ electrodes (Harvard Apparatus; $1.5 \mathrm{~mm}$ OD $\times 1.17 \mathrm{~mm}$ ID) filled with saline solution $\left(\mathrm{NaCl}, 7.5 \mathrm{~g} / 1 ; \mathrm{CaCl}_{2}, 0.21 \mathrm{~g} / 1 ; \mathrm{KCl}, 0.35 \mathrm{~g} / 1\right.$; $\mathrm{NaHCO}_{3}, 0.2 \mathrm{~g} / \mathrm{l}$ ) and in contact with a silver wire were placed on the insect antennae. The ground glass electrode entirely covered one antenna, whereas the recording electrode that was linked to an amplifier (IDAC-4, Syntech $^{\circledR}$, Hilversum, The Netherlands) with a $\times 100$ amplification was placed on the bottom of the last segment of the other antenna. A $0.5-\mathrm{cm}^{2}$ piece of filter paper that was impregnated with $10 \mu \mathrm{l}$ of the chemical under examination was placed in a Pasteur pipette. This was then used to puff an air sample in a constant $1.5 \mathrm{l} / \mathrm{min}$ airstream. Paraffin oil was used to make chemical solutions with seven concentrations ranging from $10^{-1}$ to $10^{5} \mathrm{ng} / \mu \mathrm{l}$ (by $10 \times$ increments). Electroantennograms were collected by using Autospike 3.0 (Syntech, Hilversum, The Netherlands). Stimulation with paraffin oil was used as a negative control before and after the stimulations with the seven concentrations. Time between stimulations was $30 \mathrm{sec}$. Preliminary results indicated that this length of time was adequate to allow the antenna to recover and regain its full reactivity to stimuli. Five insects from both sexes were tested with each chemical.

Behavioral Observations A single female hoverfly was placed in a cage $(30 \times 30 \times 60 \mathrm{~cm})$ with a $V$. faba plant (height, $20 \mathrm{~cm}$ ). As a positive control, the hoverflies were offered a $V$. faba plant that was infested with $1 \mathrm{~g}$ of the pea aphid A. pisum 24 hrs before the experiment started. A non- 
infested $V$. faba plant was offered to the hoverfly as negative control. A rubber septum was used as dispenser to test the behavioral activity of $(R)-(+)$-limonene (monoterpene), (Z)-3-hexenol (GLV), and E $\beta F$ (sesquiterpene). The dispenser was placed on the first pair of true leaves of a non-infested plant and contained a $100-\mu 1$ paraffin oil solution $(400 \mathrm{ng} / \mu \mathrm{l})$ of the test chemical. The solution was changed after each replication. Paraffin oil was chosen because of its chemical inertness and ability to continuously release chemicals that are diluted within it. The foraging behavior was recorded for $10 \mathrm{~min}$ by using the software The Observer5.0 ${ }^{\circledR}$ (Noldus information Technology, version 5.0, Wageningen, The Netherlands). This allows hoverfly behavior to be easily observed, subdivided, and recorded (Harmel et al. 2007). Descriptions of the four observed behavioral subdivisions are presented in Table 1. The number of eggs laid by each female was counted at the end of each observation. Experiments were conducted in a climate-controlled room at $22 \pm 1^{\circ} \mathrm{C}$. The E. balteatus females were 15 - to 30-d old, and no aphid-infested plant was offered for $24 \mathrm{hrs}$ before the experiment. Ten replications were performed for each tested chemical.

Statistical Analyses One-way analysis of variance (ANOVA) followed by Tukey's test (pairwise comparisons) was used to evaluate the EAG results. Two sample $t$ tests were used to compare EAG responses by males and females. A one-way ANOVA followed by Dunnett's test (comparison with a control) was used to compare the behavioral data observed for the four treatments compared to the control. The one sample $t$ test was applied to compare the mean number of eggs laid in behavioral assays to the " 0 " value observed with

Table 1 Description of the behavioral sequences recorded for aphidophagous hoverfly Episyrphus balteatus exposed to Vicia faba

\begin{tabular}{ll}
\hline $\begin{array}{l}\text { Observed Behavioral } \\
\text { Sequences }\end{array}$ & Descriptions \\
\hline $\begin{array}{l}\text { Immobility } \\
\text { Searching }\end{array}$ & Predator immobilized on the cage \\
Fly/cage & Predator flies in the cage \\
Fly/plant & Predator flies near the plant \\
Acceptance & Predator lands on the plant \\
Immobile/plant & Predator moves on the plant \\
Walking/plant & Predator extends its proboscis and identifies \\
Proboscis/plant & the stimulatory substrate to accept the host \\
Oviposition & Predator exhibits an abdominal protraction \\
Immobile abdomen/ & \\
plant & \\
Walking abdomen/ & \\
plant & \\
Egg laying & Oviposition \\
\hline
\end{tabular}

the control. All statistical tests were conducted by using Minitab v.14 for Windows ${ }^{\circledR}$.

\section{Results}

Electroantennography Antennal responses increased significantly in both sexes with the concentration of the tested compound (that ranged from $0.1 \mathrm{ng} / \mu \mathrm{l}$ to $0.1 \mathrm{mg} / \mu \mathrm{l}$ ). No saturation of the antenna was observed for any tested chemical. The three lowest concentrations $(0.1,1$, and $10 \mathrm{ng} / \mu \mathrm{l}) \mathrm{did}$ not elicit antennal response, regardless of the tested compound. Because we aimed to compare EAG data to results previously obtained when similar chemicals were tested on other aphid predators, we did not correct our EAG responses by taking into account their differences of volatility, as stated by Brockerhoff and Grant (1999).

EAG responses were significantly different among the five tested chemical families $\left(F_{4,152}=117.82, P<0.001\right)$, namely, monoterpenes, monoterpenes with an alcohol function, sesquiterpenes, and C6 and C9 green leaf chemicals (Fig. 1). The eight tested monoterpenes elicited electrical depolarization that ranged from -400 to $-800 \mu \mathrm{V}$, and they were all equally perceived by both sexes. Linalool induced an average depolarization of $-1,300 \mu \mathrm{V}$. This monoterpene was similarly perceived by males and females $\left(t_{\mathrm{obs}}=0.95, P=0.372\right)$. The sesquiterpene $\mathrm{E} \beta \mathrm{F}$ was the only chemical to be perceived differently by males and females $\left(t_{\mathrm{obs}}=2.62, P=0.031\right)$. The two other sesquiterpenes $(\alpha-$ humulene and $\beta$-caryophyllene) did not elicit electrical depolarization in either sex. The green leaf alcohols and aldehydes tested elicited high EAG responses, statistically equal in both males and females, ranging from $-1,750$ to $-2,250 \mu \mathrm{V}$ for the six-carbon chain GLV and from -600 to $-1,400 \mu \mathrm{V}$ for the nine-carbons chain GLV.

Behavioral Observations Hoverfly gravid females were not activated by a non-infested $V$. faba and stayed immobile during $80 \%$ of the observation time (Fig. 2). However, when an aphid-infested plant was presented, the duration of immobility was significantly reduced, and the time spent on the plant (acceptance) increased. Moreover, the number of eggs laid increased compared to non-infested plants (7.4 eggs/female; $t_{\mathrm{obs}}=7.38, P<0.001$; Fig. 3 ). (R)-(+)Limonene did not significantly attract the predatory hoverflies to the non-infested plant and did not increase the number of eggs laid, when compared with a noninfested semiochemical-free plant $\left(0.2\right.$ egg/female; $t_{\text {obs }}=$ 1.50, $P=0.084)$. ( $Z$ )-3-Hexenol presented on a non-infested plant significantly increased the mobility of females and plant acceptance. Furthermore, this GLV induced oviposition on the non-infested plant compared to oviposition on 
Fig. 1 EAG activity of female (a) and male (b) Episyrphus balteatus antennae to aphid and plant volatiles $(100 \mu \mathrm{g} / \mu \mathrm{l})$. Means $( \pm$ SE) with no letter in common are significantly different (ANOVA followed by Tukey's test, $P<0.05)$. An asterisk indicates significant difference in EAG activity between male and female antennae (twosample Student's $t$ test, $P<0.05$ ). $N=5$ for both sexes and each chemical

Fig. 2 Effect of plant and aphid volatiles on different sequences of the foraging behavior of Episyrphus balteatus females (mean duration in percent of interval, $\pm \mathrm{SE})$. Volatiles $[R$-(+)limonene, (Z)-3-hexenol, and $(E)$ - $\beta$-farnesene $(\mathrm{EBF})]$ were offered on a non-infested plant. Stars indicate significant differences from the non-infested semiochemical-free plant (=Control) for the respective behavioral sequence (ANOVA followed by Dunnett's test, $P<$ $0.05) . N=10$ for each treatment

\section{C6 Green leaf volatiles}
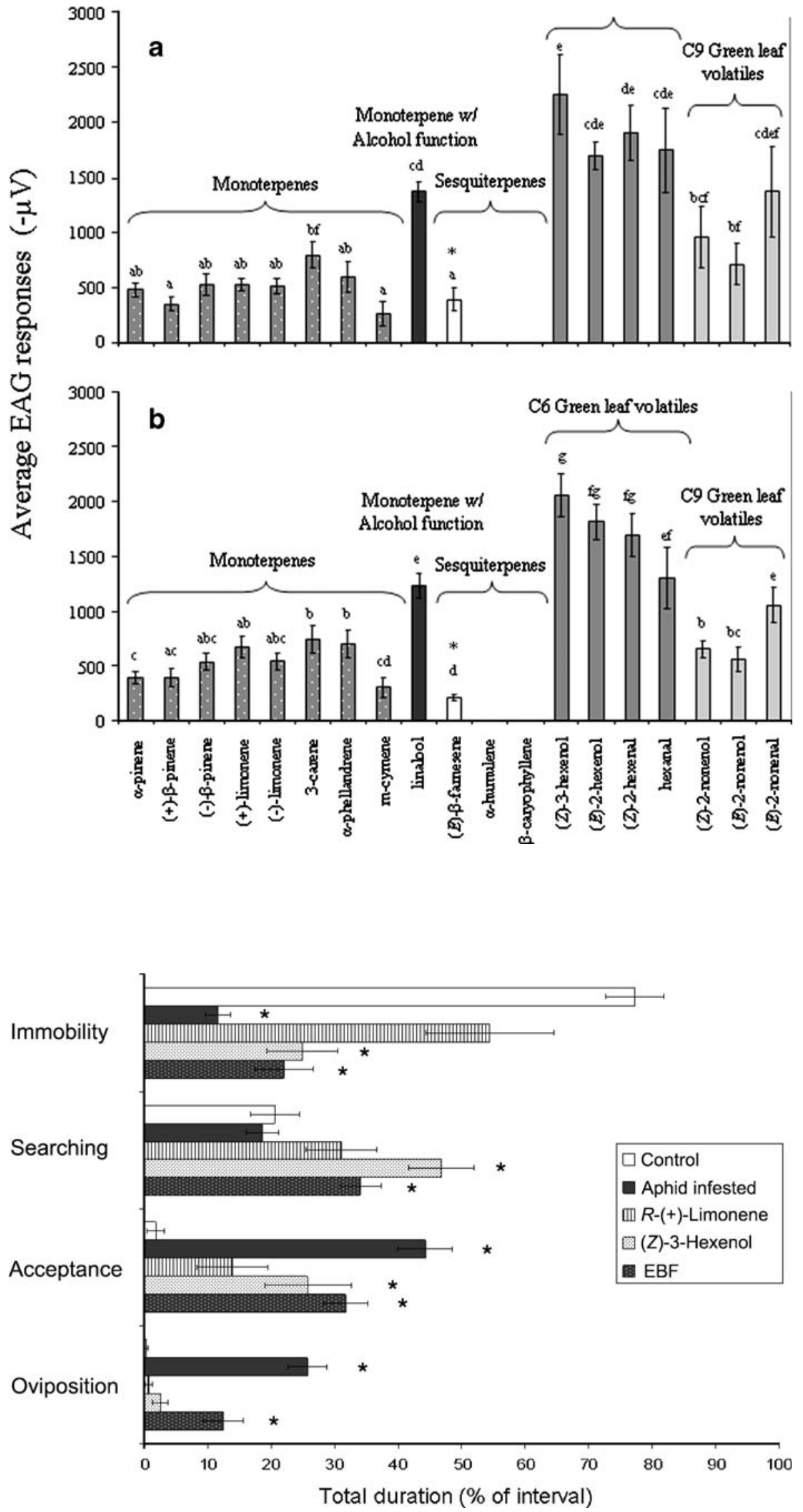
Fig. 3 Effect of plant and aphid semiochemicals on oviposition of Episyrphus balteatus females (mean number of eggs \pm SE). $n s$ No significant differences from control; $* P<0.05, * * P<0.01$, and $* * * P<0.001$ significant differences from control (onesample Student's $t$ test). $N=10$ for each treatment

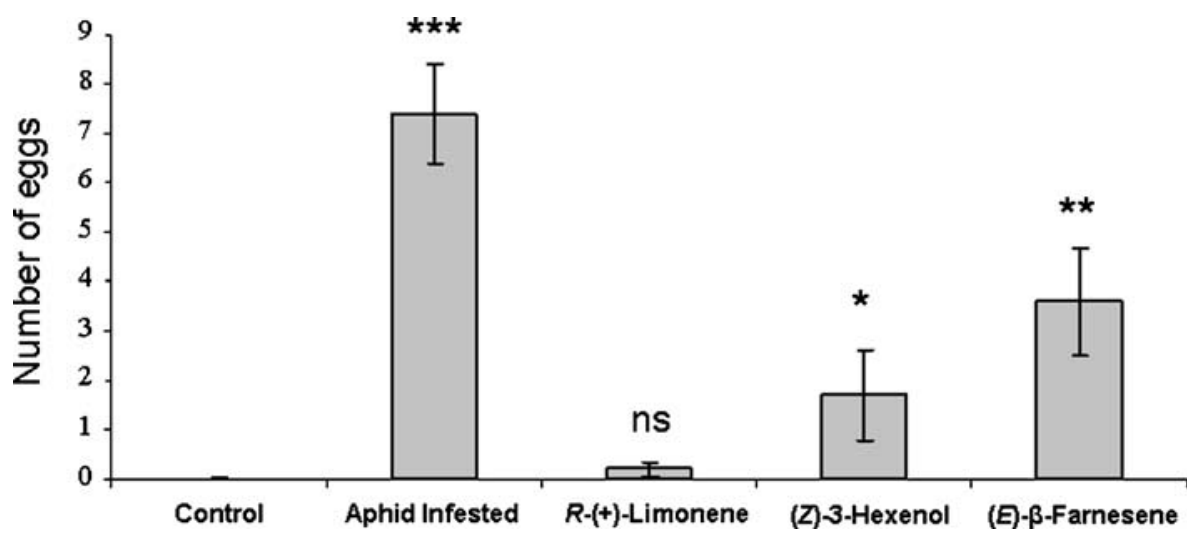

semiochemical-free, non-infested plants (1.7 eggs/female; $\left.t_{\mathrm{obs}}=1.85, P=0.049\right)$. The main compound of the aphid alarm pheromone $(\mathrm{E} \beta \mathrm{F})$ significantly increased hoverfly mobility on non-infested plants, searching duration, acceptance of the host plant, and oviposition. The mean number of eggs laid per female was 3.6. This was significantly higher than the control $\left(t_{\mathrm{obs}}=3.31, P=0.005\right)$ and lower than the number of eggs laid on an aphid-infested $V$. faba plant $\left(F_{1,18}=6.60, P=0.019\right)$.

\section{Discussion}

Tritrophic interactions among infested plants, herbivorous arthropods, and their natural enemies are complex because of the many semiochemicals typically involved. In addition to the semiochemicals emitted by herbivorous insects, most plant species respond to insect infestation by synthesizing and releasing complex blends of volatiles. These can be used by predators and parasitoids as foraging cues, thereby enhancing the plants' defense ability (Dicke et al. 1990; Dicke 1994; Turlings et al. 1995). There are several previous electrophysiological studies of antennal responses by aphid natural enemies to prey and host plant semiochemicals that include lady beetles (Coleoptera, Coccinellidae) (Zhu et al. 1999; Al Abassi et al. 2000; Verheggen et al. 2007a) and lacewings (Nevroptera, Chrysopidae) (Zhu et al. 1999; 2005). Some chemicals attract predators, but no information is available about their impact on predator foraging behavior and oviposition (Zhu et al. 1999, 2005). However, several species respond with oviposition to aphid-produced honeydew alone, whereas in others, the aphid prey itself is needed for oviposition (Steidle and van Loon 2002).

Syrphid larvae do not use semiochemicals to locate aphids, or exclusively at short distances (Bargen et al. 1998; Francis et al. 2005b). Because of their limited dispersal abilities (Chandler 1969), the choice of the oviposition site by adult females has an impact on offspring performance. Volatile organic compounds are therefore presumed to guide their foraging behavior. To the best of our knowledge, this is the first published report of successful EAG recordings from E. balteatus antennae, and we found that adult hoverflies are able to sense their environment by odors. Generalists may need to invest less time in searching particular host and prey species than specialists. Therefore, the use of infochemicals to reduce searching time should be less important (Vet and Dicke 1992). However, previous studies have indicated that the use of infochemicals for foraging is an adaptive strategy regardless of dietary specialization and that physiological constraints on sensory processing in generalists might be less severe than previously supposed (Steidle and van Loon 2003). We demonstrated in this paper that some EAG-active compounds play a key role in foraging behavior of the generalist E. balteatus. Plant and prey volatiles activate this predatory species and induce oviposition, even in absence of aphids. Additionally, we have confirmed that $E$. balteatus females do not lay eggs on a non-infested plant (Scholz and Poehling 2000).

The electrophysiologically tested terpenoids $\alpha$-pinene, $\beta$-pinene, $\alpha$-phellandrene, and limonene are not only common plant volatiles (Farag and Paré 2002; Tholl et al. 2006) but are also emitted by some aphid species such as Megoura viciae Buckton or Drepanosiphum platanoides Schrank (Francis et al. 2005a). It is not surprising that they, like other monoterpenes, elicited EAG responses in both male and female E. balteatus. (R)-(+)-Limonene did not attract the hoverflies and that the number of eggs laid by females exposed to $(R)-(+)$-limonene on a non-infested plant was not significantly different from a non-infested plant. This monoterpene is commonly found in the headspace of various plant species (Agelopoulos et al. 1999; Farag and Paré 2002; Verheggen et al. 2005) and does not provide information about prey presence on a stressed plant. This might explain why $(R)-(+)$-limonene did not provoke a behavioral effect on a gravid hoverfly female. 
Whereas the tested monoterpenes elicited small EAG responses, the GLVs showed EAG responses that were three to four times higher for the six-carbon chain GLVs, and two to three times higher for the nine-carbon chain GLVs. These responses by E. balteatus differ from those by other aphid predators (Zhu et al. 1999). In addition, our results show that (Z)-3-hexenol increased the female's mobility, plant acceptance, and oviposition activity even in the absence of prey.

$\mathrm{E} \beta \mathrm{F}$, the common aphid alarm pheromone (Francis et al. 2005a), which acts as a kairomonal substance for several aphid predators (Francis et al. 2004, 2005b; Verheggen et al. 2007a), was detected by both male and female $E$. balteatus adults. In contrast to lacewings and lady beetles, $E$. balteatus showed a sex-specific response to $\mathrm{E} \beta \mathrm{F}$ (Zhu et al. 1999; Verheggen et al. 2007a). This difference in antennal activity between sexes accentuates the importance of $\mathrm{E} \beta \mathrm{F}$ in hoverfly foraging behavior, as females are looking for a suitable oviposition site. In contrast to the strong response to $\mathrm{E} \beta \mathrm{F}$, hoverflies showed no response to the two other tested sesquiterpenes, $\alpha$-humulene and $\beta$ caryophyllene. Whereas $\beta$-caryophyllene induced antennal activity in both lady beetles and lacewings, $\alpha$-humulene was not tested on these two aphidophagous predators ( $\mathrm{Zhu}$ et al. 1999; Verheggen et al. 2007a). The lack of electrical response by E. balteatus to the two sesquiterpenes and the lower responses observed to the C9-GLV compared to the C6-GLV may also be caused by their lower volatility. Brockerhoff and Grant (1999) stated that EAG responses should be corrected by taking into account the volatility of the tested chemicals. However, $\mathrm{E} \beta \mathrm{F}$ is as volatile as $\beta$ caryophyllene and $\alpha$-humulene. E $\beta \mathrm{F}$ significantly increased hoverfly mobility, acceptance of the host plant, and the number of eggs laid (3.6 eggs/females). This aphid alarm pheromone is thus a key compound in prey-seeking behavior in aphidophagous hoverflies. Previous results have demonstrated a kairomonal role for E. balteatus larvae, which were attracted in a four-arm olfactometer (Francis et al. 2005b). In this study, we confirmed that female hoverflies are able to perceive this sesquiterpene and use it to select an oviposition site. Behavioral results obtained with an EßF-treated aphid-free plant and an aphid-infested plant were different. Therefore, the data suggest that predatory hoverfly oviposition site selection is influenced by a blend rather than a single chemical. This includes not only E $\beta F$ but also secondary metabolites related to plant damage, such as GLVs.

Acknowledgments The authors are grateful to Dr Y. Brostaux (Department of Statistic and Computer Sciences, Gembloux Agricultural University) for his help in statistical analyses and to Adam Dellinger from Penn State University (USA) for the corrections he brought to the manuscript. This research was funded by the FNRS (Fonds National de la recherche scientifique) grant (M 2.4.586.04.F).

\section{References}

Agelopoulos, N. G., Hooper, A. M., Maniar, S. P., Pickett, J. A., and WADHAMS, L. J. 1999. A novel approach for isolation of volatile chemicals released by individual leaves of a plant in situ. J. Chem. Ecol. 25:1411-1425.

Al Abassi, S. A., Birkett, M. A., Pettersson, J., Pickett, J. A., WADHAMS, L. J., and WoODCOCK, C. M. 2000. Response of the seven-spot ladybird to an alarm pheromone and an alarm pheromone inhibitor is mediated by paired olfactory cells. $J$. Chem. Ecol. 26:1765-1771.

Almohamad, R., Verheggen, F. J., Francis, F., and Haubruge, E. 2007. Predatory hoverflies select their oviposition site according to aphid host plant and aphid species. Entomol. Exp. Appl. 125:13-21.

Bargen, H., Saudhof, K., and Poehling, H. M. 1998. Prey finding by larvae and adult females of Episyrphus balteatus. Entomol. Exp. Appl. 87:245-254.

BrockerhoFf, E. G., and Grant, G. G. 1999. Correction for differences in volatility among olfactory stimuli and effect on EAG responses of Dioryctria abietivorella to plant volatiles. $J$. Chem. Ecol. 25:1353-1367.

Budenberg, W. J., and Powell, B. 1992. The role of honeydew as an oviposition stimulant for two species of syrphids. Entomol. Exp. Appl. 64:57-61.

Chandler, A. E. F. 1968. Some host-plant factors affecting oviposition by aphidophagous (Diptera: Syrphidae). Ann. Appl. Biol. 61:415-423.

Chandler, A. E. F. 1969. Locomotive behavior of first instar larvae of aphidophagous Syrphidae (Diptera) after contact with aphids. An. Behav. 17:673-678.

De Moraes, C. M., Mescher, M. C., and Tumlinson, J. H. 2001. Caterpillar-induced nocturnal plant volatiles repel conspecific females. Nature 410:577-580.

DICKE, M. 1994. Local and systemic production of volatile herbivoreinduced terpenoids: their role in plant-carnivore mutualism. $J$. Plant Physiol. 143:465-472.

DiCKE, M., and SABELIS, M. W. 1988. Infochemical terminology: based cost-benefit analysis rather than origin of compounds. Funct. Ecol. 2:131-139.

Dicke, M., Beek, T. A. V., Posthumus, M. A., Dom, N. B., Bokhoven, H. V., and Groot, A. D. 1990. Isolation and identification of volatiles kairomones that affects acarine predator-prey interactions. Involvement of host plant in its production. J. Chem. Ecol. 16:381-396.

Entwistle, J. C., and DiXON, A. F. G. 1989. The effect of augmenting grain aphid (Sitobium avenae) numbers in a field of winter wheat in spring on the aphids abundance in summer and its relevance to the forecasting of outbreaks. Ann. Appl. Biol. 114:397-408.

FARAG, M. A., and PARÉ, P. W. 2002. C6-Green leaf volatiles trigger local and systemic VOC emissions in tomato. Phytochemistry 61:545-554.

Francis, F., Lognay, G., and Haubruge, E. 2004. Olfactory responses to aphid and host plant volatile releases: E- $\beta$ Farnesene, an effective kairomone for the predator Adalia bipunctata. J. Chem. Ecol. 30:741-755.

Francis, F., VANDERmoten, S., Verheggen, F. J., Lognay, G., and HaUbruge, E. 2005a. Is (E)- $\beta$-farnesene the only volatile terpenoid in aphids. J. Appl. Entomol. 129:6-11.

Francis, F., Martin, T., Lognay, G., and Haubruge, E. 2005 b. Role of (E)- $\beta$-farnesene in systematic aphid prey location by Episyrphus balteatus larvae (Diptera: Syrphidae). Eur. J. Entomol. 102:431-436.

Frechette, B., Dixon, A. F. G., Alauzet, C., and Hemptinne, J.-L. 2004. Age and experience influence patch assessment for oviposition by an insect predator. Ecol. Entomol. 29:578-583. 
Harmel, N., Almohamad, R., Fauconnier, M.-L., Du Jardin, P., Verheggen, F., Marlier, M., Haubruge, E., and Francis, F. 2007. Role of terpenes from aphid-infested potato on searching and oviposition behavior of the hoverfly predator Episyrphus balteatus. Insect Science 14:57-6.

NAUlt, L. R., EDWARDS, L. J., and STYER, W. E. 1973. Aphid alarm pheromones: Secretion and reception. Environ. Entomol. 2:101-105.

NoRDLUND, D. A., and LEWIS, W. J. 1976. Terminology of chemical releasing stimuli in intraspecific and interspecific interactions. $J$. Chem. Ecol. 2:211-220.

PARÉ, P. W., and TumLinson, J. 1997. De novo biosynthesis of volatiles induced by insect herbivory in cotton plants. Plant Physiol. 114:1161-1167.

SADEGHI, H., and GiLBerT, F. 2000a. Oviposition preferences of aphidophagous hoverflies. Ecol. Entomol. 25:91-100.

SADEGHI, H., and GILBERT, F. 2000b. Aphid suitability and its relationship to oviposition preference in predatory hoverflies. $J$. Anim. Ecol. 69:771-784.

SADEGHI, H., and GILBERT, F. 2000c. The effect of egg load and host deprivation on oviposition behaviour in aphidophagous hoverflies. Ecol. Entomol. 25:101-108.

SANDERS, W. 1983. The searching behaviour of gravide Syrphus corollae Fabr. (Diptera: Syrphidae) and its depending on the optical cues. Z. Angew. Zool. 70:235-247.

SCHNEIDER, F. 1969. Bionomics and physiology of aphidophagous Syrphidae. Annu. Rev. Entomol. 14:103-121.

Scholz, D., and Poehling, H. M. 2000. Oviposition site selection of Episyrphus balteatus. Entomol. Exp. Appl. 94:149-158.

Steidle, J. L. M., and VAN LoOn, J. J. A. 2002. Chemoecology of parasitoid and predator oviposition behaviour, pp. 291-317, in M. Hilker, and T. Meiners (eds.). Chemoecology of Insect Eggs and Egg DepositionBlackwell, Berlin.

SteIDLE, J. L. M., and VAN LOON, J. J. A. 2003. Dietary specialization and infochemical use in carnivorous arthropods: testing a concept. Entomol. Exp. Appl. 108:133-148.

Sutherland, J. P., Sullivan, M. S., and Poppy, G. M. 1999. The influence of floral character on the foraging behaviour of the hoverfly, Episyrphus balteatus. Entomol. Exp. Appl. 93:157-164.

Sutherland, J. P., Sullivan, M. S., and Poppy, G. M. 2001. Oviposition behaviour and host colony size discrimination in Episyrphus balteatus (Diptera: Syrphidae). Bull. Entomol. Res. 91:411-417.

Tanaka, S., Yasuda, A., Yamamoto, H., and Nozaki, H. 1975. A general method for the synthesis of 1,3-dienes. Simple syntheses of $\beta$ - and trans- $\alpha$-farnesene from farnesol. J. Am. Chem. Soc. 97:3252-3254.

Tenhumberg, B., and Poenling, H. M. 1991. Studies on the efficiency of syrphid larvae, as predators of aphids on winter wheat, pp. 281288, in L. Polgar, R. J. Chambers, A. F. G. Dixon, and I. Hodek (eds.). Behaviour and Impact of AphidophagaSPB Academic Publishing BV, The Hague, The Netherlands.
Tholl, D., Boland, W., Hansel, A., Loreto, F., ÖSE, U. S. R., and SCHNITZLER, J.-P. 2006. Practical approaches to plant volatile analysis. Plant $J$. 45:540-560.

Tumlinson, J. H., Turlings, T. C. J., and Lewis, W. J. 1992. The semiochemical complexes that mediate insect parasitoid foraging. Agr. Zool. Reviews 5:221-252.

Turlings, T. C. J., Tumlinson, J. H., and Lewis, W. J. 1990. Exploitation of herbivore-induced plant odor by host-seeking parasitic wasps. Science 250:1251-1253.

TuRLingS, T. C. J., and TumLinson, J. H. 1992. Systemic release of chemical signals by herbivore-injured corn. Proc. Natl. Acad. Sci. USA 89:8399-8402.

Turlings, T. C. J., Loughrin, J. H., MC Call, P. J., OSE, U. S. R., LEWIS, W. J., and TumLinson, J. H. 1995. How caterpillardamaged plants protect themselves by attracting parasitic wasps. Proc. Natl. Acad. Sci. USA 92:4169-4174.

Vanhaelen, N., Haubruge, E., Gaspar, C., and Francis, F. 2001. Oviposition preferences of Episyrphus balteatus. Med. Fac. Landbouw. Univ.Gent. 66/2a.

VAnHAELEN, N., GaSPar, C., F, and F. 2002. Influence of prey host plant on a generalist aphidophagous predator: Episyrphus balteatus (Diptera: Syrphidae). Eur. J. Entomol. 99:561-564.

Verheggen, F. J., Arnaud, L., Capella, Q., Francis, F., and Haubruge, E. 2005. Perception of aphid infested tomato plant volatiles by the predator Episyrphus balteatus. Comp. Biochem. Phys 3:141A.

Verheggen, F. J., Fagel, Q., Heuskin, S., Lognay, G., Francis, F., and HAUBRUGE, E. 2007a. Electrophysiological and behavioral responses of the multicolored Asian lady beetle, Harmonia axyridis Pallas, to sesquiterpene semiochemicals. J. Chem. Ecol. 33:2148-2155.

Verheggen, F. J., Ryne, C., Olsson, C., Arnaud, L., Lognay, G., Persson, D., Haubruge, E., and Löfstedt, C. 2007b. Electrophysiological and behavioural study of some secondary metabolites in the confused flour beetle, Tribolium confusum. J. Chem. Ecol. 33:525-539.

VET, L. E. M., and DiCKE, M. 1992. Ecology of infochemical use by natural enemies in a tritrophic context. Annu. Rev. Entomol. 37:141-172.

Videla, M., Valladares, G., and Salvo, A. 2006. A tritrophic analysis of host preference and performance in a polyphagous leafminer. Entomol. Exp. Appl. 121:105-114.

Zhu, J., Cossé, A. A., OBrycki, J. J., Boo, K. S., and BAKer, T. C. 1999. Olfactory reactions of the twelve-spotted lady beetle, Coleomegilla maculata and the green lacewing, Chrysoperla to semiochemicals released from their prey and host plant: Electroantennogram and behavioral responses. J. Chem. Ecol. 5:11631177.

ZhU, J., OBRYcki, J. J., OChIENG, S., BAKer, T. C., and Pickett, J. 2005. Attraction of two lacewing species to volatiles produced by host plants and aphid prey. Naturwissenschaften 92:277-281. 